\title{
Adaptation to climate change in Africa Synergies with biodiversity and forest
}

\author{
Johnson Nkem', Monica Idinoba', Maria Brockhaus' \\ Fobissie Kalame ${ }^{1}$ and Adriaan Tas ${ }^{2}$
}

'Tropical Forests and Climate Change Adaptation (TroFCCA), Center for International Forestry Research

2 Stockholm Environmental Institute

Forests, and the biodiversity contained within them play key roles in supporting national economic activities and providing livelihood portfolios for many in Africa. They provide valuable ecosystem services such as climate regulation, hazard protection, water conservation, watershed protection, and also provisioning goods such as fuelwood, foods and nutritional supplements, and medicinal products etc. Forests are therefore at the frontline in moderating climate impacts on Africa by reducing exposure to climate extremes such as heat, drought and floods, and also the sensitivity and adaptive capacity of forest dependent people. Inarguably, forests should play a major role in national development strategies and be the entry point for climate change adaptation in Africa.

Climate change, biodiversity and forest loss are issues inextricably interlinked and need to be addressed simultaneously. This is especially important with regard to climate change adaptation in Africa particularly with the emergence of contemporary global challenges such as the current food crisis. The same drivers of biodiversity loss in Africa are also largely responsible for increased vulnerability to climate change, most importantly drought, poverty, low institutional capacities that affect the adaptive capacity of communities, and inappropriate policies with preferences for short-term economic gains. The synergy between adaptation to climate change and biodiversity conservation requires a unifying strategy to enhance the sustainability of the forest resource pools on which poor communities directly depend for their livelihoods. This approach has recently been acknowledged in discussions on cooperation between conventions within the Convention for Biological Diversity (CBD) and the United Nations Framework Convention on Climate Change (UNFCCC), both of which have stressed the need for common approaches in their national implementation, which also provides a cost-saving option for African countries.

In spite of the frequency of droughts and floods in several parts of Africa, there are very limited national or regional institutional structures dealing with climate change adaptation, and also for biodiversity conservation outside designated protected areas, such as there is for food and water in response to drought and desertification. The role of biodiversity and the integration of biodiversity conservation into climate change adaptation programs remain insufficiently addressed.

Tropical forests have important roles on the African landscape but they are currently experiencing rapid deforestation and degradation with significant reduction in forest cover and fragmentation across the landscape. Over 4 million ha/yr of forest in Africa is estimated to be lost annually since 2000 ( $\left.{ }^{3} \mathrm{FAO} 2005\right)$. 


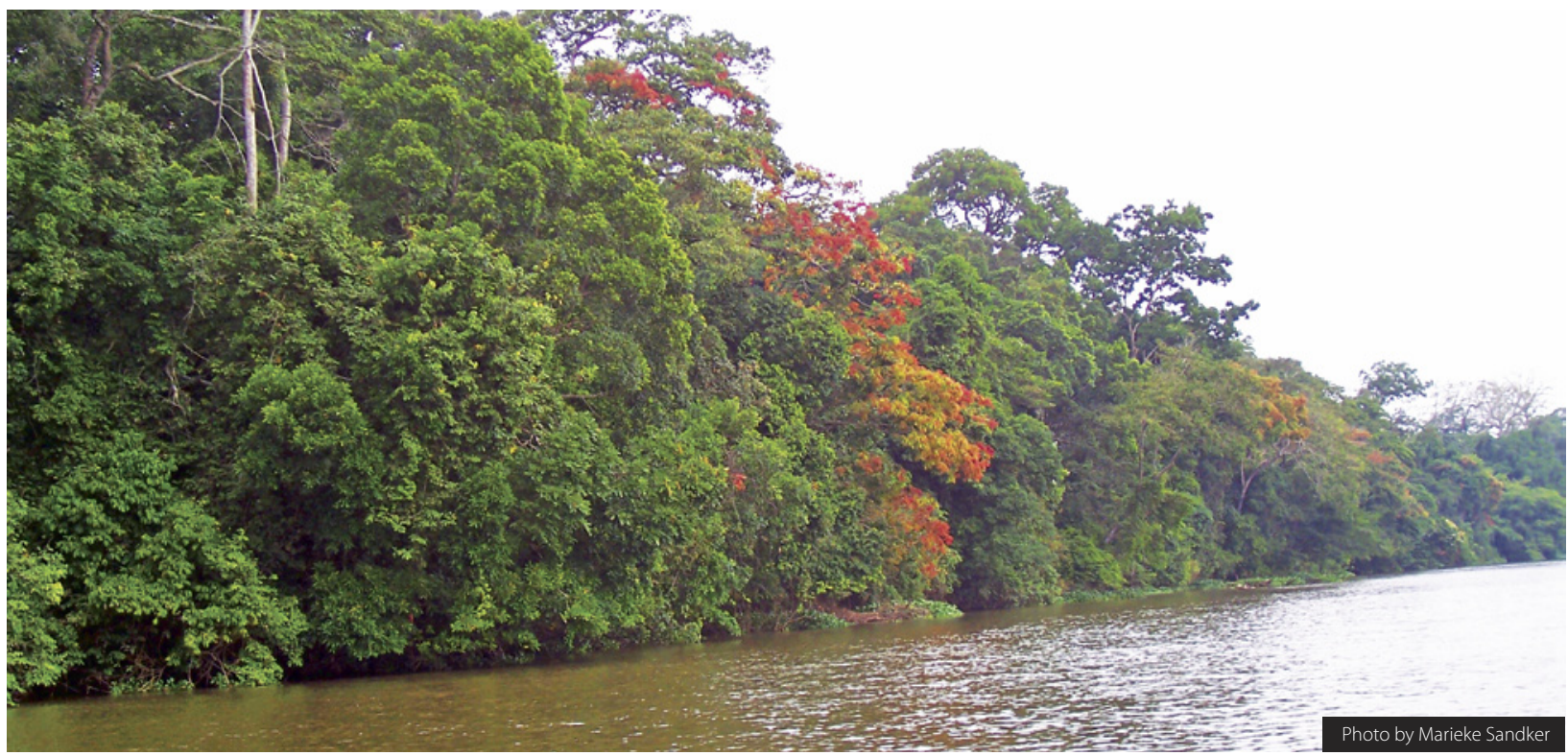

African Tropical Forests, Cameroon

Carbon emissions resulting from this annual loss in forest and other vegetation are estimated to range from 440 to over $1200 \mathrm{Mt} \mathrm{CO} /$ yr in sub-Saharan Africa (IPCC (2007)).

Tropical forests provide livelihood opportunities for over 1.6 billion people worldwide living in extreme poverty ( ${ }^{4}$ UNCCD et al. 2004). They also provide an indispensable asset for contributing to national poverty reduction strategies and, consequently, the realization of some of the millennium development goals (MDG 1 and 7) in developing countries.
Forest ecosystems in tropical Africa are important repositories for vital livelihood resources and ecosystem services, and, at the same time, constitute major wildlife habitats including corridors that allow for migration facilitating coping with climate risks. The biodiversity of tropical forests in Africa is being threatened by a range of human activities such as mining, habitat loss due to conversion to agricultural land and logging, over-exploitation for fuel wood, food, medicinal plants, overgrazing, water catchment and river channel destructions some of which are in response to climate change pressures. Such activities

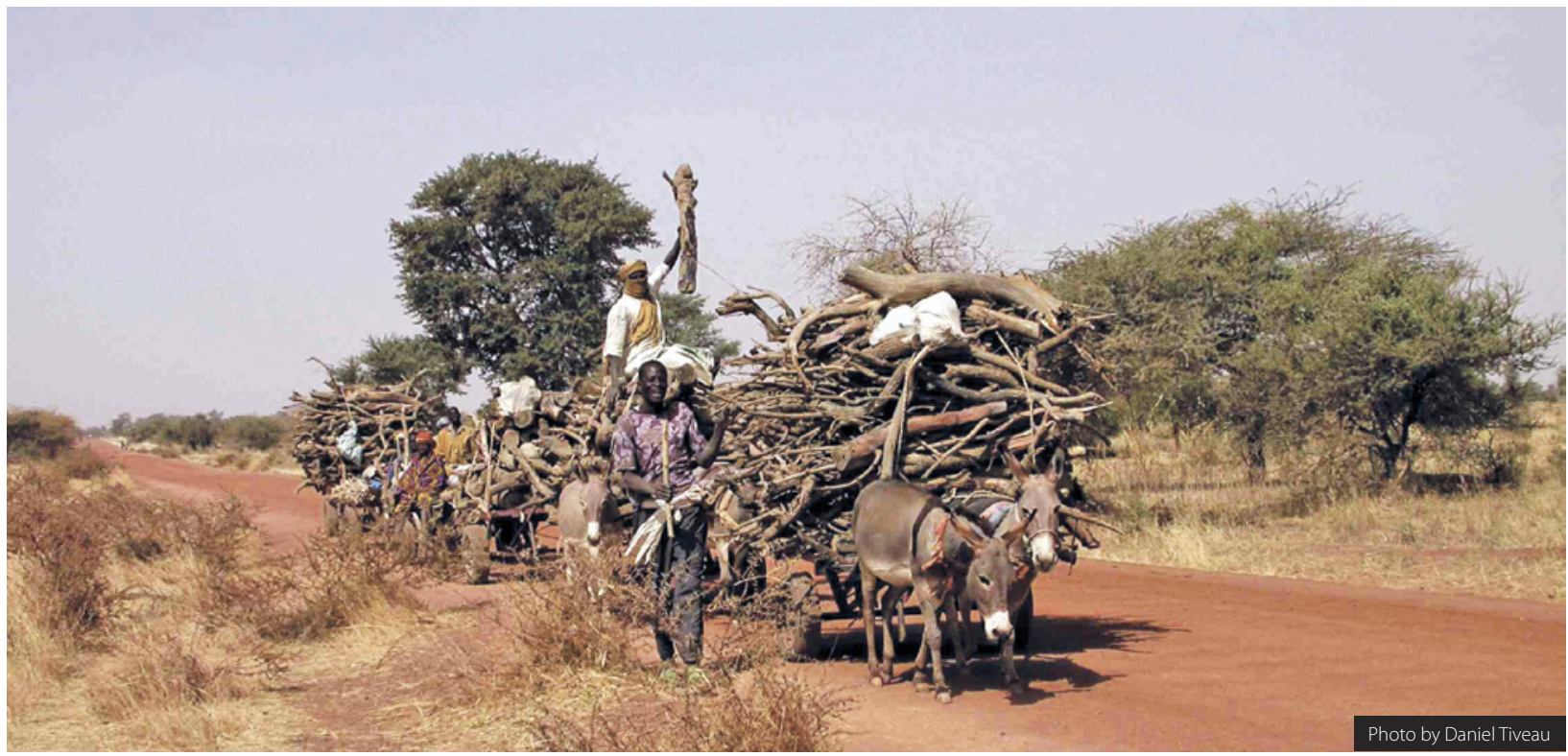

Fuelwood, one of Non-Timber Forest Products in Africa 
have resulted in habitat modifications and the loss of endemic species and have also endangered other species.

Several studies and predictive models have strongly emphasized the vulnerability of African tropical forest biodiversity to various climate change scenarios, and the resulting direct consequences on wildlife populations, and the livelihoods of humans. Such loss of biodiversity amplifies the vulnerability of the continent to the impacts of climate change. According to the IPCC ${ }^{1}$, although there are some conservation plans for ecosystems and biodiversity implementation in many parts of the world, these plans have failed to consider current and projected climate change impacts. The conservation of biodiversity is strongly targeted at protected areas, yet adaptation options need to be designed and executed outside these areas, particularly in complex human-dominated landscapes. Climate change adaptation strategies in Africa should therefore simultaneously have an integrated plan for biodiversity conservation and livelihood adaptation strategies that match local resource use patterns without jeopardizing the resilience of the forest ecosystem to climate change impacts.

\section{Recommendations for}

\section{synergies with biodiversity and forests}

1) It is important to recognise the linkages between biodiversity loss and vulnerability to climate change in Africa, and how these could exacerbate poverty and further compromise food security

2) Adaptation strategies should encourage the conservation of habitats and biodiversity (fauna and flora) that underlies livelihood adaptation especially in rural areas

3) There is need to provide and support participatory actions and multi-stakeholder discussion platforms that encourage the integration of biodiversity conservation into climate change adaptation strategies, and beyond protected areas

4) It is essential to build the capacities of actors, sectors and institutions in their use and management of multiple forest resources across scales (local, national and regional) and over time in order to balance economic growth and livelihood adaptation without jeopardising the resilience of the forest ecosystem to climate change

5) Implement institutional arrangements and governance structures that promote synergy in the planning and implementation of agro-ecosystems and forestry programmes for mitigation and adaptation projects to derive maximum benefit to the environment as well as the local communities or economies
6) Encourage afforestation and reforestation programmes that are in compliance with climate, community and biodiversity standards

7) Building regional institutional capacity and decisionsupport systems for managing transboundary resources that ensure quality, regulation capacity and demand in the use of resources

8) Planning management strategies that are long-term and dynamic, and which encourage the sharing of information, intelligence and experiences in tracking natural resource flow across territorial boundaries in curbing illegal trade and practices that affect biodiversity conservation and adaptation.

9) Integrate landscape approaches in land use management to avoid maladaptation in other sectors and section of the communities

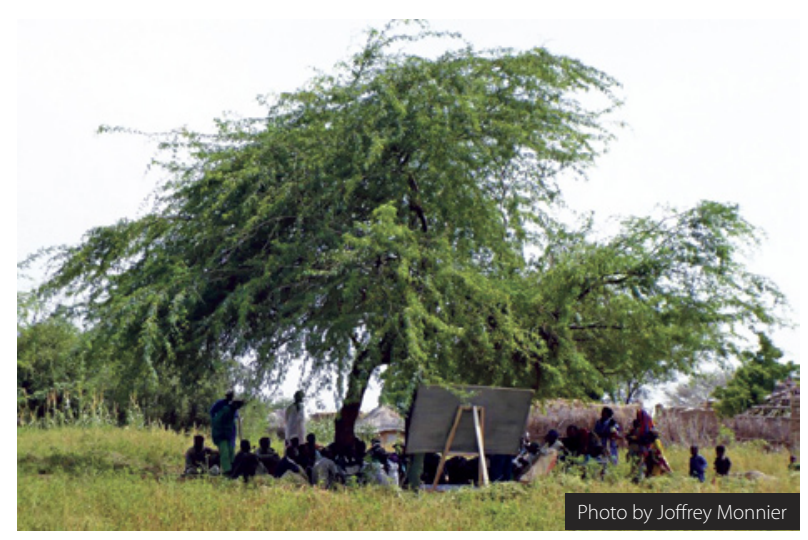

Multi-stakeholders Meeting, Burkina Faso

\section{The significance of synergies with biodiversity and forests}

The significance in jointly addressing biodiversity and forests for adaptation to climate change in Africa include:

- The linkages between livelihood benefits of biodiversity conservation and climate change adaptation could serve as incentives for change of practices such as bush burning and overgrazing that could result in maladaptation

- A space for a direct impact in policy implementation is expected as new forest governance reform schemes are currently ongoing in Africa such as the Forest Law Enforcement Governance and Trade (FLEGT)

- Building climate change adaptation capacity into transboundary resource management strategic plans will reinforce regional initiatives such as wildlife corridors (e.g. Northern Savannah Biodiversity Conservation Project), river basin authorities (e.g. Nile, Niger Rivers), and forest management (e.g. Congo Basin Forests) in response to climate variability in Africa 
- Integrating biodiversity conservation strategies into mainstream forestry and climate change adaptation programmes will permit the communities directly involved to appraise the performance of climate change adaptation strategies in terms of both livelihood and biodiversity outcomes

- Cross-national collaboration will be facilitated through networking and the identification of best practices in various regions, sharing of experiences and information of success stories

- Building on initiatives that commonly contribute to the implementation of the CBD and the UNFCCC, including the process of national adaptation programmes of action (NAPAs) and the framework for achieving the 2010 targets set at the Conference of Parties of the CBD² in 2002

- Building biodiversity assessment and management capacity of local communities to enhance their adaptive capacities to climate change especially under the new forest governance reform programmes currently in most countries in the region

\section{Footnotes}

${ }^{1}$ IPCC Technical Paper V (2002) Climate Change and Biodiversity

${ }^{2}$ Secretariat of the Convention on Biological Diversity (2006) Global Biodiversity Outlook 2

${ }^{3}$ FAO Global forest resources assessment (2005) FAO Forestry Paper 147

${ }^{4}$ UNCCD, UNCBD \& UNFCCC, 2004. Final Report on the Workshop on forest and forest ecosystems: Promoting synergy in the three Rio conventions. 5-7 April 2004, Viterbo, Italy

For further information, please contact:

Johnson Nkem j.nkem@cgiar.org

Monica Idinoba m.idinoba@cgiar.org

Maria Brockhaus m.brockhaus@cgiar.org

Fobissie Kalame f.kalame@cgiar.org

Adrian Tas adriaantas.sei@gmail.com

\section{http://www.cifor.cgiar.org/trofcca/}

For general inquiries: cifor@cgiar.org

Center for International Forestry Research (CIFOR) advances human well-being, environmental conservation, and equity by conducting research to inform policies and practices that affect forests in developing countries. CIFOR is one of 15 centres within the Consultative Group on International Agricultural Research (CGIAR). CIFOR's headquarters are in Bogor, Indonesia. It also has offices in Asia, Africa and South America. CIFOR works in over 30 countries worldwide and has links with researchers in 50 international, regional and national organisations. www.cifor.cgiar.org 